\title{
Experimental research on the elastic deformation mode of 1C45 (1.0503) SR EN 10083- 1.2 rolled steel fastened between the centers of an universal lathe
}

\author{
Lucian Tăbăcaru*, Gavril Muscă and Alexandra Dzedzid \\ Gheorghe Asachi Technical University of Iasi, Faculty of Machine Manufacturing and Industrial \\ Management, Iasi, Romania
}

\begin{abstract}
Elastic deformations of the technological system occur during the mechanical treatment of a blank, regardless of the manner in which it is fastened. The elastic deformation of the blank is significant especially when machining shaft-like parts. The purpose of our research is to compare the mathematical model of blank deformation to the experimental model when the blank, which is a part belonging to the shaft class, is fastened between centers.
\end{abstract}

\section{Introduction}

The technological system may suffer elastic deformations under the action of exterior forces. These deformations occur on the direction of action of the forces. System rigidity is defined as its capacity to resist deformation. The forces that act in the technological system are the cutting forces. The $P_{y}$ force is usually used to determine system rigidity. The proper approach would be to calculate the resultant of the three forces first and then the rigidity [1]. The rigidity of a system is calculated as the component/deformation ratio:

$$
R=\frac{P_{y}}{y}[\mathrm{daN} / \mathrm{mm}]
$$

The force/deformation ratio was determined experimentally, by entering different values of the $P_{y}$ cutting force into the technological system and then measuring the deformation triggered by them. Figure 2 shows the deformation law applying to regular machine tools where the $y_{0}$ represents plastic deformation is actually the weight shift in view of the processing of the clearances occurring between the assembly components. The surface between the curves is the mechanical work meant to resist the friction forces between components on clearance processing, on unevenness processing. Further to repeated loading on the same component, the surface between the two curves decreases and the mechanical work diminishes. This surface shape is called rigidity hysteresis, [2-4]:

\footnotetext{
*Corresponding author: 1tabacaru@tcm.tuiasi.ro
} 


$$
R_{\text {med }}=\frac{A B}{O B}=\operatorname{tg} \alpha-\text { mean value of rigidity }
$$

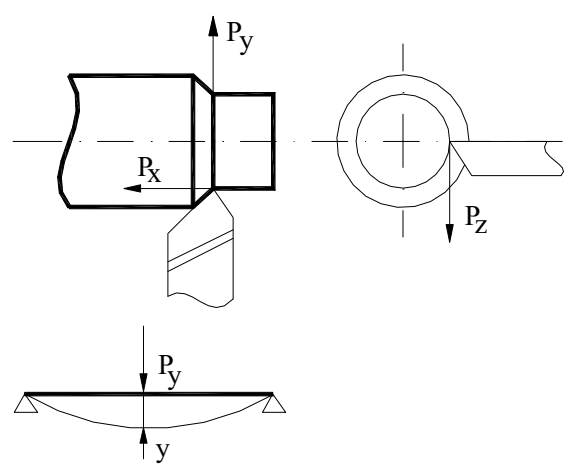

Fig. 1. Elastic deformation caused by the $P_{y}$ force.

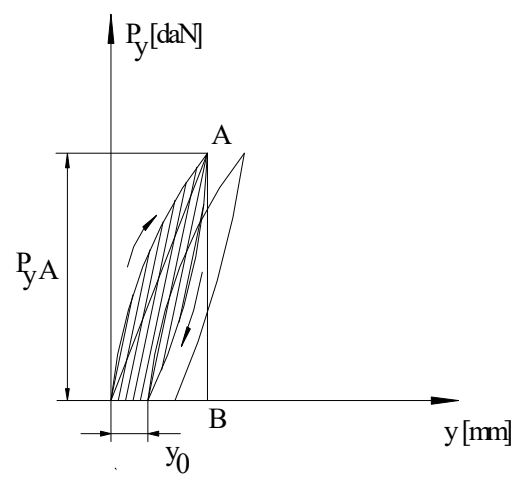

Fig. 2. Graphical representation of loaddeformation.

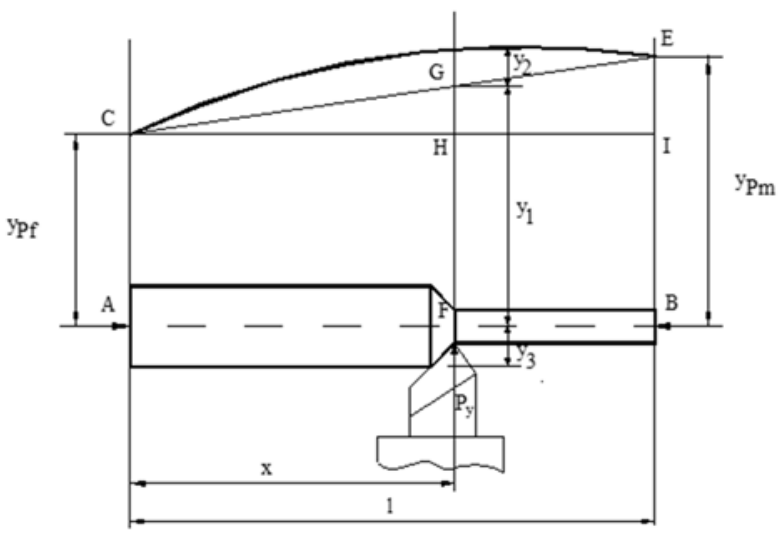

Fig. 3. Pattern used to determine errors caused by elastic deformation when the blank is fastened between centers.

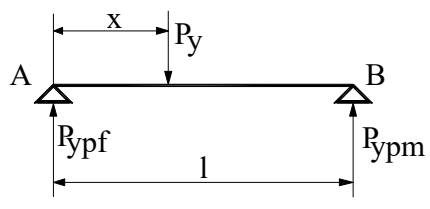

Fig. 4. $P_{y}$ force distribution on supports.

\section{Mathematical model}

The work pattern shown is used to determine the processing error caused by the elastic deformation of the technological system when the blank is placed between centers (Figure 3) [1]. The following technological system deformations occur under the influence of the $P_{y}$ force:

- Headstock shift;

- Tailstock shift;

- Part shift in section $x$ caused by headstock and tailstock shift;

- Part arrow in section $x$;

- Tool and tool support shift under the action of $P_{y}$;

The problem arising here is to determine the extent to which the $P_{y}$ force acts on the tailstock and the extent to which the same force acts on the headstock (Figure 4): 


$$
\begin{aligned}
& t_{p r}-t_{r}=t_{r e m}=y_{1}+y_{2}+y_{3} \\
& y_{1}=F H+G H=y_{P f}+\frac{x}{l} \cdot\left(y_{p m}-y_{p f}\right) \\
& \triangle C G H \approx \Delta C E I \\
& \frac{G H}{C H}=\frac{E I}{C I} \\
& G H=\frac{x}{l} \cdot\left(y_{p m}-y_{p f}\right) \\
& P_{y_{p f}}=P_{y} \cdot \frac{l-x}{l} \\
& P_{y_{p m}}=P_{y} \cdot \frac{x}{l} \\
& y_{p t}=\frac{P_{y_{p f}}}{R_{p f}}=\frac{P_{y}}{R_{p f}} \cdot \frac{l-x}{l} \\
& y_{p m}=\frac{P_{y_{p m}}}{R_{p m}}=\frac{P_{y}}{R_{p m}} \cdot \frac{x}{l} \\
& y_{1}=\frac{P_{y}}{R_{p f}} \cdot \frac{l-x}{l}+\frac{x}{l}\left(\frac{P_{y}}{R_{p m}} \cdot \frac{x}{l}-\frac{P_{y}}{R_{p f}} \cdot \frac{l-x}{l}\right) \\
& y_{2}=\frac{P_{y}}{R_{p f}}\left(\frac{l-x}{l}-\frac{x}{l} \cdot \frac{l-x}{l}\right)+\frac{P_{y}}{R_{p m}} \cdot \frac{x^{2}}{l^{2}} \\
& y_{1}=\frac{P_{y}}{R_{p f}} \cdot\left(\frac{l-x}{l}\right)^{2}+\frac{P_{y}}{R_{p m}} \cdot\left(\frac{x}{l}\right)^{2} \\
& y_{2}=\frac{P_{y}}{3 E I} \frac{x^{2}(l-x)^{2}}{l}-\text { arrow ratio } \\
& y_{3}=\frac{P_{y}}{R_{s c}} \\
& t_{p r}=t_{r}+\frac{P_{y}}{R_{p f}}\left(\frac{l-x}{l}\right)^{2}+\frac{P_{y}}{R_{p m}}\left(\frac{x}{l}\right)^{2}+\ldots+\frac{P_{y}}{3 E I} \cdot \frac{x^{2}(l-x)^{2}}{l}+\frac{P_{y}}{R_{s c}}
\end{aligned}
$$

If $P_{y}=c \cdot k \cdot t_{r}$ and $t_{r}=\frac{t_{p r}}{1+A}$, then: 


$$
t_{r e m}=t_{p r}-t_{r}=t_{p r}\left[1-\frac{1}{1+A}\right]
$$

When a batch of parts is processed, the prescribed depth ranges from to with a variation which causes an error on the $y$ direction.

$$
\Delta_{y}=t_{r e m_{\max }}-t_{r e m_{\min }}=\left[t_{p r_{, a x}}-t_{p r_{\min }}\right] \cdot\left[1-\frac{1}{1+A}\right]
$$

On the diameter: $\Delta D=2 \Delta_{y}$. Assuming that the machine tool is very rigid, which means that tailstock, headstock and tool shifts are absent, $y_{1}$ and $y_{3}$ are null and hence the processing error is the result of the elastic deformation of the part. The shape of the part is shown in Figure 5. When the part is very rigid, (i.e. it does not undergo any elastic deformation) and assuming that the tool and the support are very rigid, the shape of the part is influenced solely by $y_{1}$. The processing error will only be determined by $y_{l}$ (Figs. 5 and 6 ):

$$
t_{r e m}=y_{1}=\frac{P_{y}}{R_{p f}}\left(\frac{l-x}{l}\right)^{2}+\frac{P_{y}}{R_{p m}}\left(\frac{x}{l}\right)^{2}
$$

A shape error also occurs, which is a quadric $[5,6]: t_{r e m}=y_{\max }-y_{\min }$

In order to determine $y_{\min }$ we will send to zero:

$$
\begin{gathered}
t_{r e m}^{\prime}=0 \\
t_{r e m}^{\prime}=\frac{P_{y}}{R_{p f}} \cdot \frac{2 x}{l^{2}}-\frac{P_{y}}{R_{p f}} \cdot \frac{2 l}{l^{2}}+\frac{P_{y}}{R_{p m}} \cdot \frac{2 x}{l^{2}}=0 \\
\frac{x}{l}\left[\frac{1}{R_{p f} \cdot l}+\frac{1}{R_{p m} \cdot l}\right]=\frac{1}{R_{p f} \cdot l} \Rightarrow \frac{\mathrm{x}}{1}=\frac{R_{p m}}{R_{p f}+R_{p m}}
\end{gathered}
$$

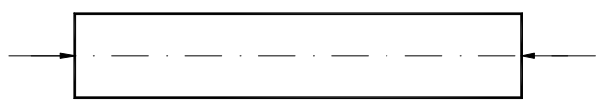

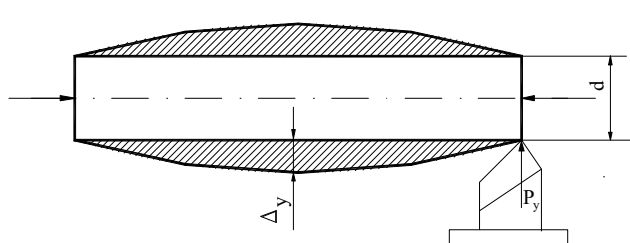

Fig. 5. Shape of the part when the machine tool is very rigid.

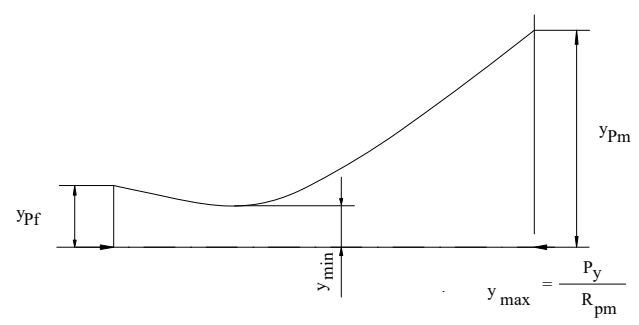

Fig. 6. Processing error caused solely by $y_{l}$. 


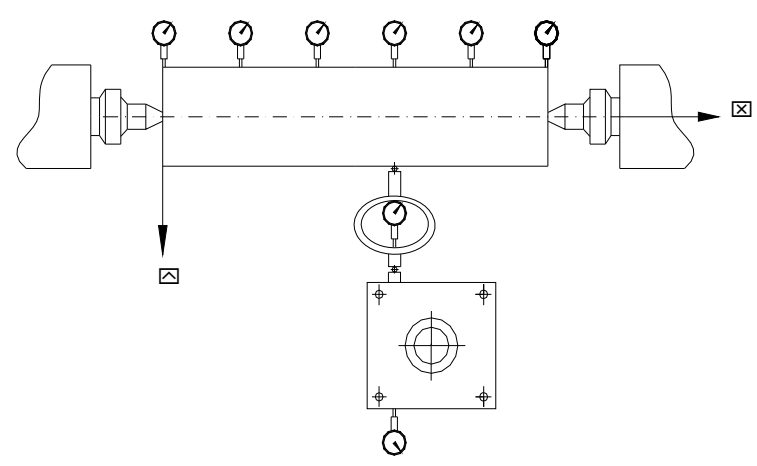

Fig. 7. Experimental pattern used to assess the static elastic deformation of various components subject to the $P_{y}$ force.

By replacing in $t_{\text {rem }}$ we can determine $y_{\min }$ :

$$
\begin{gathered}
y_{\min }=\frac{P_{y}}{R_{p f}}\left[1-\frac{R_{p m}}{R_{p f}+R_{p m}}\right]^{2}+\frac{P_{y}}{R_{p m}}\left(\frac{R_{p m}}{R_{p f}+R_{p m}}\right)^{2} \cdot\left[\frac{R_{p f}+R_{p m}-R_{p m}}{R_{p m}+R_{p m}}\right]^{2} \\
y_{\min }=P_{y} \cdot \frac{R_{p f}}{\left(R_{p f}+R_{p m}\right)^{2}}+P_{y} \cdot \frac{R_{p m}}{\left(R_{p f}+R_{p m}\right)^{2}}=\frac{P_{y}}{R_{p f}+R_{p m}}
\end{gathered}
$$

\section{Experimental model}

In this paper we aim at determining the processing errors caused by the elastic deformations of the technological system when placing parts between centers. For this experiment we used a $1000 \mathrm{~mm}$ long and $40 \mathrm{~mm}$ wide $1 \mathrm{C} 45$ (1.0503) metal bar, which observed the SR EN 10083-1,2 requirements, and a SN 250 machine tool.

The method consists of the static simulation of the forces generated during the turning process; the elastic deformations of the various components are determined after the force applied on the work piece has been increased, which should provide data on the rigidity of the turning system Figure 7.

Indeed, from the viewpoint of the various methods of work piece fastening, it may be interesting to assess the system's resistance to deformation caused by the cutting forces. Several simplifying hypotheses were considered for the case described in Figure 7, namely that the $P_{y}$ force.

As shown in Figure 7, a dynamometer is placed between the tool holder and the work piece in order to read at any time the force entered into the system, by the rotation of one of the dynamometer nuts.

We used dial gauges placed every $170 \mathrm{~mm}$ and at the ends of the blank, in order to read the elastic deformation of the work piece subject to different $P_{y}$ load forces, which materialize various cutting forces.

The dynamometer touched the work piece and a parallelepiped piece replacing the turning tool, by means of two metal balls, with the aim of ensuring the best possible transmission of the radial force.

$$
t_{r e m}=y_{\text {max }}-y_{\text {min }}=\frac{P_{y}}{R_{p m}}-\frac{P_{y}}{R_{p f}+R_{p m}}
$$


In order to determine the highest value of the $P_{y}$ experimental force that may be used during the experimental research, we considered hard turning using a regular cutting tool. The work piece was made of carbon steel and used the following mode of operation: cutting depth, $t=4 \mathrm{~mm}$ and $s=0.4 \mathrm{~mm} /$ rot. In this case, the $P_{y}$ force may be calculated using the following relation $[1-4]$ :

$$
P_{y}=C_{F y} t^{x} S^{y} H B^{n}
$$

Where $C_{F y}$ is a coefficient the value of which depends on the cutting tool type, on the material the cutting tool and the work piece are made of $C_{F y}=0.027$ and $\mathrm{HB}$ is work piece material hardness $\mathrm{HB}=225-1 \mathrm{C} 45$ (1.0503).

A $P_{y}$ force of variable value, ranging from 0 to $160 \mathrm{daN}$, was entered into the system by means of the dynamometer, and then the $P_{y}$ force was decreased to $0 \mathrm{daN}$; the deformation values shown in Tables 1-5 were read by the dial gauges for each $P_{y}$ force value [4]. The exponents are $\mathrm{x}=0.9, \mathrm{y}=0.75, \mathrm{n}=2.0$.

When the cutting depth is $t=4 \mathrm{~mm}$ and the cutting feed is $s=0.4 \mathrm{~mm} / \mathrm{rot}, P_{y}=0.02740 .9$ $0.40 .752252=238 \mathrm{daN}$ for $1 \mathrm{C} 45$. On the other hand, the forces generated in the work piece during the experimental research should not exceed the maximum elastic deformation values applying to the work piece material.

Table 1. Elastic deformation read in various points on the part for various $P_{y}$ force values applied at $x=170 \mathrm{~mm}$.

\begin{tabular}{|c|c|c|c|c|c|c|c|c|c|c|c|c|c|}
\hline \multirow[t]{3}{*}{$\begin{array}{l}\text { Exp. } \\
\text { No. }\end{array}$} & \multirow{3}{*}{$\begin{array}{c}\text { Force } \mathrm{P}_{y} \\
\text { [div]/[daN] } \\
\text { (increments) } \\
\text { applied to } x=170 \\
\mathrm{~mm}\end{array}$} & \multicolumn{12}{|c|}{$\begin{array}{c}\text { Elastic deformation } \\
y[\mathrm{~mm}]\end{array}$} \\
\hline & & \multicolumn{2}{|c|}{$\begin{array}{c}\text { Rotating } \\
\text { center - } \\
\text { headstock }\end{array}$} & \multicolumn{2}{|c|}{$\mathrm{x}=170$} & \multicolumn{2}{|c|}{$\mathrm{x}=340$} & \multicolumn{2}{|c|}{$\mathrm{x}=510$} & \multicolumn{2}{|c|}{$x=680$} & \multicolumn{2}{|c|}{$\begin{array}{l}\text { Rotating center - } \\
\text { tailstock }\end{array}$} \\
\hline & & C & D & $\mathrm{C}$ & D & C & D & C & D & C & D & $\mathrm{C}$ & D \\
\hline 1 & $0 / 0$ & 0.0 & 0.0 & 0.0 & 0.01 & 0.0 & 0.01 & 0 & 0.02 & 0 & 0.01 & 0.0 & 0.12 \\
\hline 2 & $25 / 20$ & 0.01 & 0.01 & 0.06 & 0.06 & 0.09 & 0.10 & 0.08 & 0.12 & 0.15 & 0.18 & 0.15 & 0.18 \\
\hline 3 & $50 / 40$ & 0.02 & 0.02 & 0.13 & 0.14 & 0.19 & 0.20 & 0.18 & 0.22 & 0.13 & 0.20 & 0.12 & 0.32 \\
\hline 4 & $75 / 60$ & 0.03 & 0.04 & 0.20 & 0.22 & 0.29 & 0.30 & 0.29 & 0.31 & 0.20 & 0.22 & 0.23 & 0.44 \\
\hline 5 & $100 / 80$ & 0.04 & 0.05 & 0.28 & 0.29 & 0.38 & 0.40 & 0.37 & 0.41 & 0.27 & 0.29 & 0.33 & 0.59 \\
\hline 6 & $125 / 100$ & 0.06 & 0.06 & 0.35 & 0.37 & 0.49 & 0.50 & 0.47 & 0.51 & 0.34 & 0.36 & 0.49 & 0.69 \\
\hline 7 & $150 / 120$ & 0.07 & 0.08 & 0.42 & 0.44 & 0.59 & 0.61 & 0.56 & 0.60 & 0.41 & 0.42 & 0.60 & 0.78 \\
\hline 8 & $175 / 140$ & 0.08 & 0.09 & 0.50 & 0.51 & 0.70 & 0.71 & 0.68 & 0.70 & 0.49 & 0.49 & 0.71 & 0.80 \\
\hline 9 & $200 / 160$ & 0.09 & 0.09 & 0.57 & 0.57 & 0.80 & 0.80 & 0.77 & 0.77 & 0.56 & 0.56 & 0.85 & 0.85 \\
\hline
\end{tabular}

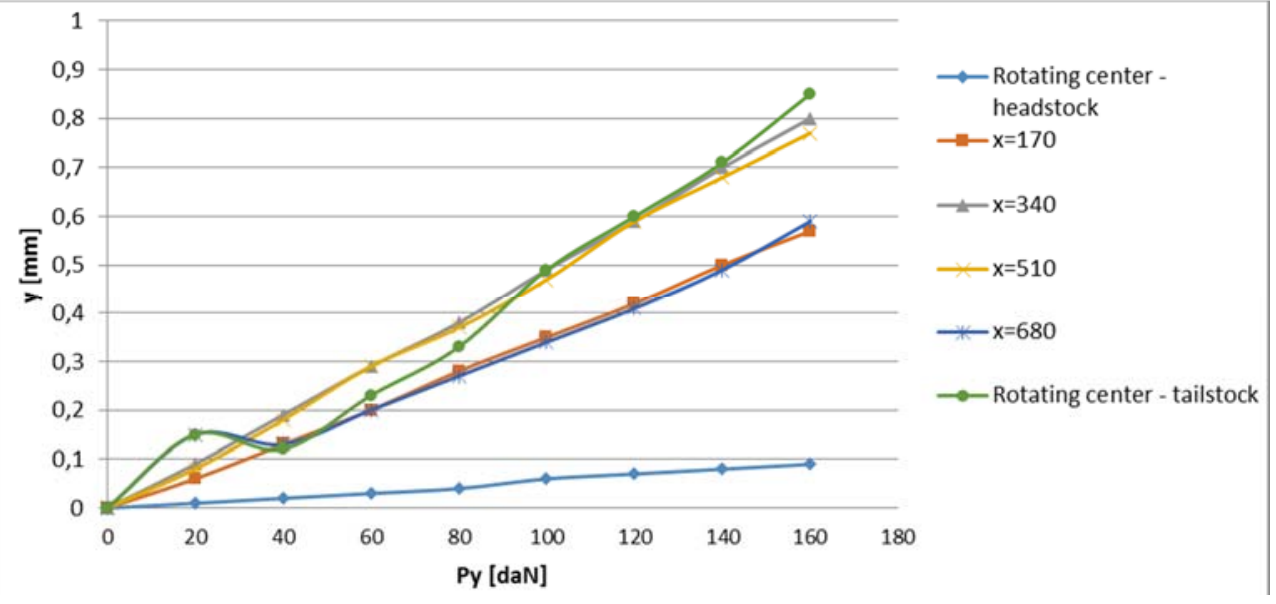

Fig. 8. Graph of load elastic deformations for different processing system components for 1C45, force $P_{y}[\mathrm{daN}]$ applied to $x=170 \mathrm{~mm}$. 
Table 2. Elastic deformation read in various points on the part for various $P_{y}$ force values applied at $x=340 \mathrm{~mm}$.

\begin{tabular}{|c|c|c|c|c|c|c|c|c|c|c|c|c|c|}
\hline \multirow{3}{*}{$\begin{array}{l}\text { Exp } \\
\text { No. }\end{array}$} & \multirow{3}{*}{$\begin{array}{l}\text { Force } P_{y} \\
\text { [div]/ } \\
\text { [daN] } \\
\text { applied } \\
\text { at } \\
x=340 \\
\text { mm }\end{array}$} & \multicolumn{12}{|c|}{$\begin{array}{c}\text { Elastic deformation } \\
y[\mathrm{~mm}]\end{array}$} \\
\hline & & \multicolumn{2}{|c|}{$\begin{array}{l}\text { Rotating center - } \\
\text { headstock }\end{array}$} & \multicolumn{2}{|c|}{$x=170$} & \multicolumn{2}{|c|}{$x=340$} & \multicolumn{2}{|c|}{$\mathrm{x}=510$} & \multicolumn{2}{|c|}{$\mathrm{x}=680$} & \multicolumn{2}{|c|}{$\begin{array}{l}\text { Rotating } \\
\text { center - } \\
\text { tailstock }\end{array}$} \\
\hline & & C & D & c & D & C & D & c & D & C & D & $\mathrm{c}$ & $\mathrm{D}$ \\
\hline 1 & 0,0 & 0.0 & 0.01 & \begin{tabular}{|l|l}
0.0 \\
\end{tabular} & 0.01 & 0.0 & 0.01 & 0 & 0.02 & 0.0 & 0.01 & 0.0 & 0.01 \\
\hline 2 & $25 / 20$ & 0.1 & 0.2 & 0.09 & 0.1 & \begin{tabular}{|l|l|}
0.11 \\
\end{tabular} & 0.14 & 0.16 & 0.19 & 0.11 & 0.13 & 0.08 & 0.17 \\
\hline 3 & $50 / 40$ & 0.2 & 0.3 & 0.19 & 0.21 & 0.26 & 0.30 & 0.33 & 0.34 & 0.22 & 0.24 & 0.30 & 0.45 \\
\hline 4 & $75 / 60$ & 0.35 & 0.4 & 0.29 & 0.3 & 0.41 & 0.44 & \begin{tabular}{|l}
0.49 \\
\end{tabular} & 0.52 & 0.38 & 0.39 & 0.52 & 0.61 \\
\hline 5 & 10080 & 0.5 & 0.6 & 0.39 & 0.41 & 0.57 & 0.60 & 0.65 & 0.68 & 0.50 & 0.54 & 0.72 & 0.89 \\
\hline 6 & $125 / 100$ & 0.6 & 0.7 & 0.48 & 0.51 & 0.74 & 0.77 & 0.83 & 0.87 & 0.63 & 0.66 & 0.94 & 1.05 \\
\hline 7 & $150 / 120$ & 0.75 & 0.8 & 0.59 & 0.60 & 0.89 & 0.92 & 1.00 & 1.03 & 0.76 & 0.79 & 1.20 & 1.32 \\
\hline 8 & $175 / 140$ & 0.9 & 0.95 & $\begin{array}{l}0.67 \\
\end{array}$ & 0.70 & 1.04 & 1.09 & 1.18 & 1.20 & 0.89 & 0.91 & 1.50 & 1.59 \\
\hline 9 & $200 / 160$ & 0.1 & 0.1 & 0.8 & 0.80 & 1.20 & 1.20 & 1.35 & 1.35 & 1.05 & 1.05 & 1.86 & 1.86 \\
\hline
\end{tabular}

Table 3. Elastic deformation read in various points on the part for various $P_{y}$ force values applied at $x=510 \mathrm{~mm}$.

\begin{tabular}{|c|c|c|c|c|c|c|c|c|c|c|c|c|c|}
\hline \multirow[t]{3}{*}{$\begin{array}{l}\text { Exp. } \\
\text { No. }\end{array}$} & \multirow{3}{*}{$\begin{array}{c}\text { Force } \mathrm{P}_{y} \\
{[\text { div]/[daN] }} \\
\text { applied at } \\
x=510 \mathrm{~mm}\end{array}$} & \multicolumn{12}{|c|}{$\begin{array}{c}\text { Elastic deformation } \\
y[\mathrm{~mm}]\end{array}$} \\
\hline & & \multicolumn{2}{|c|}{$\begin{array}{c}\text { Rotating } \\
\text { center - } \\
\text { headstock }\end{array}$} & \multicolumn{2}{|c|}{$x=170$} & \multicolumn{2}{|c|}{$\mathrm{x}=340$} & \multicolumn{2}{|c|}{$x=510$} & \multicolumn{2}{|c|}{$\mathrm{x}=680$} & \multicolumn{2}{|c|}{$\begin{array}{l}\text { Rotating } \\
\text { center - } \\
\text { tailstock }\end{array}$} \\
\hline & & C & D & C & D & C & D & C & D & C & D & c & D \\
\hline 1 & 0,0 & 0.0 & 0.01 & 0.0 & 0.005 & 0.0 & 0.01 & 0.0 & 0.01 & 0.0 & 0.01 & 0.0 & 0.02 \\
\hline 2 & $25 / 20$ & 0.10 & 0.15 & 0.09 & 0.14 & 0.13 & 0.19 & 0.17 & 0.22 & 0.13 & 0.17 & 0.26 & 0.30 \\
\hline 3 & $50 / 40$ & 0.20 & 0.25 & 0.19 & 0.22 & 0.29 & 0.34 & 0.36 & 0.48 & 0.27 & 0.28 & 0.57 & 0.65 \\
\hline 4 & $75 / 60$ & 0.35 & 0.4 & 0.29 & 0.33 & 0.45 & 0.50 & 0.55 & 0.60 & 0.37 & 0.39 & 0.86 & 0.92 \\
\hline 5 & $100 / 80$ & 0.40 & 0.45 & 0.38 & 0.40 & 0.61 & 0.65 & 0.75 & 0.83 & 0.58 & 0.63 & 1.22 & 1.39 \\
\hline 6 & $125 / 100$ & 0.5 & 0.55 & 0.48 & 0.51 & 0.78 & 0.84 & 0.94 & 1.10 & 0.73 & 0.81 & 1.58 & 1.73 \\
\hline 7 & $150 / 120$ & 0.65 & 0.7 & 0.57 & 0.60 & 0.94 & 0.95 & 1.13 & 1.20 & 0.89 & 0.97 & 2.04 & 2.09 \\
\hline 8 & $175 / 140$ & 0.7 & 0.75 & 0.66 & 0.69 & 1.13 & 1.16 & 1.33 & 1.37 & 1.07 & 1.10 & 2.64 & 2.88 \\
\hline
\end{tabular}

Table 4. Elastic deformation read in various points on the part for various $P_{y}$ force values applied at $\mathrm{x}=680 \mathrm{~mm}$.

\begin{tabular}{|c|c|c|c|c|c|c|c|c|c|c|c|c|c|}
\hline \multirow[t]{3}{*}{$\begin{array}{l}\text { Exp. } \\
\text { No. }\end{array}$} & \multirow{3}{*}{$\begin{array}{c}\text { Force } \mathrm{P}_{y} \\
\text { [div]/[daN] } \\
\text { applied at } \\
\mathrm{x}=680 \mathrm{~mm}\end{array}$} & \multicolumn{12}{|c|}{$\begin{array}{c}\text { Elastic deformation } \\
\mathrm{y}[\mathrm{mm}]\end{array}$} \\
\hline & & \multicolumn{2}{|c|}{$\begin{array}{l}\text { Rotating center } \\
\text { - headstock }\end{array}$} & \multicolumn{2}{|c|}{$\mathrm{x}=170$} & \multicolumn{2}{|c|}{$\mathrm{x}=340$} & \multicolumn{2}{|c|}{$\mathrm{x}=510$} & \multicolumn{2}{|c|}{$x=680$} & \multicolumn{2}{|c|}{$\begin{array}{l}\text { Rotating } \\
\text { center - } \\
\text { tailstock }\end{array}$} \\
\hline & & c & D & C & D & c & D & c & D & c & D & c & D \\
\hline 1 & $0 \%$ & 0 & 0.0 & 0 & 0.01 & 0 & 0.01 & 0 & 0.02 & 0 & 0.01 & 0 & 0.2 \\
\hline 2 & $25 / 20$ & 0.05 & 0.1 & 0.7 & 0.11 & 0.12 & 0.17 & 0.17 & 0.31 & 0.16 & 0.19 & 0.32 & 0.42 \\
\hline 3 & $50 / 40$ & 0.1 & 0.15 & 0.14 & 0.15 & 0.24 & 0.27 & 0.26 & 0.36 & 0.22 & 0.27 & 0.64 & 0.69 \\
\hline 4 & $75 / 60$ & 0.1 & 0.2 & 0.21 & 0.22 & 0.36 & 0.40 & 0.42 & 0.45 & 0.35 & 0.39 & 1.08 & 1.11 \\
\hline 5 & $100 / 80$ & 0.25 & 0.3 & 0.28 & 0.30 & 0.50 & 0.54 & 0.58 & 0.60 & 0.49 & 0.55 & 1.53 & 1.83 \\
\hline 6 & $125 / 100$ & 0.35 & 0.4 & 0.36 & 0.41 & 0.63 & 0.69 & 0.75 & 0.79 & 0.65 & 0.69 & 2.26 & 2.48 \\
\hline 7 & $150 / 120$ & 0.4 & 0.45 & 0.44 & 0.49 & 0.77 & 0.80 & 0.93 & 0.97 & 0.82 & 0.85 & 2.82 & 2.90 \\
\hline 8 & $175 / 140$ & 0.5 & 0.55 & 0.52 & 0.55 & 0.92 & 0.94 & 1.11 & 1.14 & 1.01 & 1.03 & 3.9 & 4.08 \\
\hline 9 & $200 / 160$ & 0.58 & 0.58 & 0.61 & 0.61 & 1.10 & 1.10 & 1.33 & 1.33 & 1.21 & 1.21 & 4.28 & 4.28 \\
\hline
\end{tabular}

Table 5. Elastic deformation read in various points on the part for various $P_{y}$ force values applied at $x=850 \mathrm{~mm}$.

\begin{tabular}{|c|c|c|c|c|c|c|c|c|c|c|c|c|c|}
\hline \multirow[t]{3}{*}{$\begin{array}{l}\text { Exp. } \\
\text { No. }\end{array}$} & \multirow{3}{*}{$\begin{array}{l}\text { Force } \mathrm{P}_{\mathrm{y}} \\
\text { [div][daN] } \\
\text { applied at } \\
x=850 \mathrm{~mm}\end{array}$} & \multicolumn{12}{|c|}{$\begin{array}{c}\text { Elastic deformation } \\
y[\mathrm{~mm}]\end{array}$} \\
\hline & & \multicolumn{2}{|c|}{$\begin{array}{l}\text { Rotating } \\
\text { center - } \\
\text { headstock }\end{array}$} & \multicolumn{2}{|c|}{$x=170$} & \multicolumn{2}{|c|}{$\mathrm{x}=340$} & \multicolumn{2}{|c|}{$\mathrm{x}=510$} & \multicolumn{2}{|c|}{$\mathrm{x}=680$} & \multicolumn{2}{|c|}{$\begin{array}{l}\text { Rotating } \\
\text { center - } \\
\text { tailstock }\end{array}$} \\
\hline & & C & D & C & D & C & D & C & D & C & D & C & D \\
\hline 1 & $0 / 0$ & 0 & 0 & 0 & 0.05 & 0 & 0.01 & 0 & 0.01 & 0 & 0.01 & 0 & 0.2 \\
\hline 2 & $25 / 20$ & 0.01 & 0.05 & 0.4 & 0.55 & 0.009 & 0.10 & 0.08 & 0.11 & 0.05 & 0.10 & 0.31 & 0.50 \\
\hline 3 & $50 / 40$ & 0.02 & 0.08 & 0.7 & 0. & 0.18 & 0.21 & 0.17 & 0.20 & 0.16 & 0.19 & 0.81 & 1.00 \\
\hline 4 & $75 / 60$ & 0.05 & 0.01 & 0.11 & 0.12 & 0.26 & 0.28 & 0.25 & 0.26 & 0.22 & 0.28 & 1.20 & 1.34 \\
\hline 5 & $100 / 80$ & 0.1 & 0.15 & 0.15 & 0.17 & 0.35 & 0.39 & 0.35 & 0.38 & 0.31 & 0.33 & 1.88 & 2.00 \\
\hline 6 & $125 / 100$ & 0.15 & 0.2 & 0.21 & 0.22 & 0.45 & 0.47 & 0.465 & 0.47 & 0.41 & 0.44 & 2.78 & 3.00 \\
\hline 7 & $150 / 120$ & 0.2 & 0.25 & 0.24 & 0.25 & 0.56 & 0.57 & 0.59 & 0.63 & 0.51 & 0.53 & 3.68 & 3.98 \\
\hline 8 & $175 / 140$ & 0.3 & 0.35 & 0.39 & 0.42 & 0.68 & 0.70 & 0.74 & 0.78 & 0.65 & 0.67 & 4.08 & 4.16 \\
\hline 9 & $200 / 160$ & 0.4 & 0.4 & 0.56 & 0.56 & 0.86 & 0.86 & 0.96 & 0.96 & 0.91 & 0.91 & 5.3 & 5.30 \\
\hline
\end{tabular}




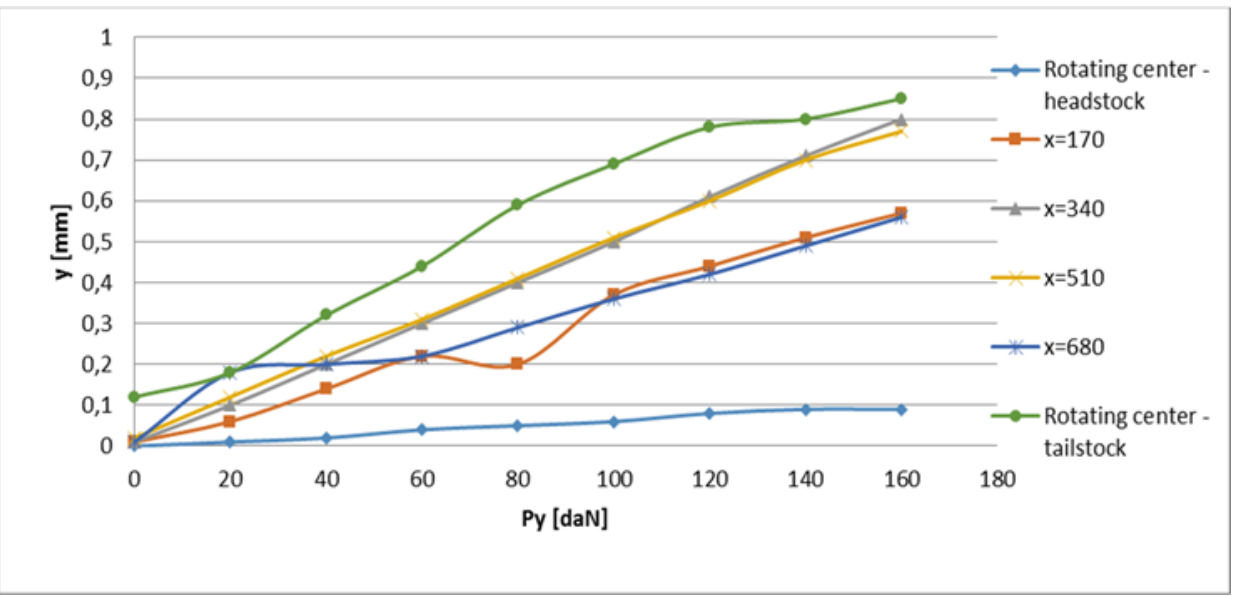

Fig. 9. The graph of the elastic deformations at discharge for different components of the processing system for $1 \mathrm{C} 45$, force $P_{y}[\mathrm{daN}]$ applied to $x=170 \mathrm{~mm}$.

\section{Conclusions}

Further to the analysis of the tables containing the experimental values and of the graphical representations in Figures 8 and 9, we may conclude that:

- A cutting force of $P_{y}=160 \mathrm{daN}$ applied at the $x=850 \mathrm{~mm}$ distance from the left end of the work piece causes a maximum deformation value in the tailstock area of $y=5.30 \mathrm{~mm}$.

- In Table 4, the unloading curve read in the tailstock area for the $P_{y}$ force applied at the $x=680 \mathrm{~mm}$ distance leads of a maximum plastic deformation value of $y=0.2 \mathrm{~mm}$; this value proves that the technological system components shifted to resist the friction forces occurring in the system and to absorb the system clearances;

- Our research confirmed that, among the components in direct contact with the work piece, the universal support had the highest static rigidity;

- The elastic deviation of the work piece is one of the factors that may impede upon the accuracy of the processing during the turning process. The extent of this deviation significantly depends on the static rigidity of the components of the processing systems;

- Our research fully confirms the mathematical model, when the blank is fastened between centers.

\section{References}

1. I.E. Manole, G. Nagîţ, Feed rate influence on burnishing degree in ceramic ball burnishing process. Academic Journal of Manufacturing Engineering, 9, 2 (2011)

2. V.V. Merticaru. V. Chirilă, E. Suso-Sanchez, M. San Juan-Blanco, Statistical quality control for postgraduate courses (in Romanian), (Publishing House of "Dunărea de Jos" Universitary Foundation, Galaţi, 2000)

3. V.V. Merticaru, G. Nagit, B. Pralea, R. Oana, Convergent use of advanced $\mathrm{CAD} / \mathrm{CAE} / \mathrm{CAM}$ capabilities for sustainable integrated engineering. Academic Journal of Manufacturing Engineering 12, 20, (2014)

4. L. Tabacaru, O.V. Pruteanu, Conception and management of manufacturing technologies (in Romanian) (Junimea Publishing Iasi, 2007) 